\title{
We like to share
}

\author{
Nature Physics is one of 23 Springer Nature journals involved in a pilot scheme to make published papers readily \\ available via ResearchGate.
}

T here's no doubt about it, this is an era for creative thinking in the world of scientific publishing. The push for open science has forced publishers to rethink existing models and to look for new ways to disseminate research. The latest chapter in this story involves a partnership between Springer Nature and social-media platform ResearchGate (https://www. researchgate.net), which will make future Nature Physics articles - and some of our back-catalogue - available to view and download without a subscription.

ResearchGate was founded in 2008 by scientists Ijad Madisch, Sören Hofmayer and Horst Fickenscher. Based in Berlin, the platform boasts a global network comprising more than 15 million scientists who participate by uploading their research output - primarily papers and populating their profiles. The goal of the platform is to facilitate collaboration between users and to make research open to all, so although creating a user account requires affiliation with a recognized institution, anyone can consult the platform and read its content.
In the campaign for transparency, there will inevitably be a few ruffled feathers. In September 2017, the International Association of Scientific Technical and Medical Publishers (STM) contacted ResearchGate to express concern over their article-sharing practices. Five publishers subsequently formed a coalition for 'responsible sharing' (https://www. responsiblesharing.org/), which issued takedown requests. Coalition members Elsevier and the American Chemical Society later filed lawsuits in Germany and the US.

Other publishers chose a different route. In April 2018, Cambridge University Press, Thieme and Springer Nature formed an agreement with ResearchGate, expressing a commitment to find a way of sharing scientific articles without compromising the rights of publishers and authors ${ }^{1}$. The new partnership between Springer Nature and ResearchGate forms the next - seemingly logical, if bold - step in this direction. Currently pitched as a threemonth pilot scheme beginning 1 March 2019 , the initiative makes articles from 23 different subscription-based Nature journals accessible, including those from Nature and Nature Physics, dating back to November $2017^{2}$.

In practice, the work will be done behind the scenes. The final published versions of Nature Physics articles will be directly uploaded to our authors' ResearchGate profiles, although whether or not they remain there will be the author's prerogative.

It goes without saying that we're excited to be taking part in this scheme, which we see as an excellent complement to the SharedIt initiative, allowing anyone with a subscription to generate links to free readable versions of our papers. We would encourage all our authors to spread the news about both options to give their papers the widest possible audience.

Published online: 1 April 2019

https://doi.org/10.1038/s41567-019-0503-y

References

1. Bengsch, D. ResearchGate welcomes cooperation agreement with three major scientific publishers. https://go.nature.com/2TJIuVn (ResearchGate, 19 April 2018).

2. ResearchGate and Springer Nature embark on pilot to deliver seamless discovery and an enhanced reading experience. https://go.nature.com/2JuvNJg (Springer Nature, 1 March 2019).

\section{Black hole son}

The British Royal Mint has issued a commemorative coin in honour of Stephen Hawking.

A $s$ the United Kingdom peers into a metaphorical black hole of its own making, one of its most accomplished sons has been honoured with the minting of a 50 pence coin (pictured), featuring artist Edwina Ellis's impression of a black hole.

On the occasion of his 60th birthday, Stephen Hawking described how he came up with Hawking radiation ${ }^{1}$ - the stunning revelation that black holes are not entirely black. Characterizing it as a 'warm-up exercise' for his attempt to unite general relativity with quantum theory, Hawking expressed surprise that his calculation predicted a black-hole emission. His fondness for the discovery was manifest in his request that the formula relating the entropy of a black hole to the area of its event horizon be etched into his tombstone ${ }^{2}$. The new coin will see this celebrated equation circulated widely.

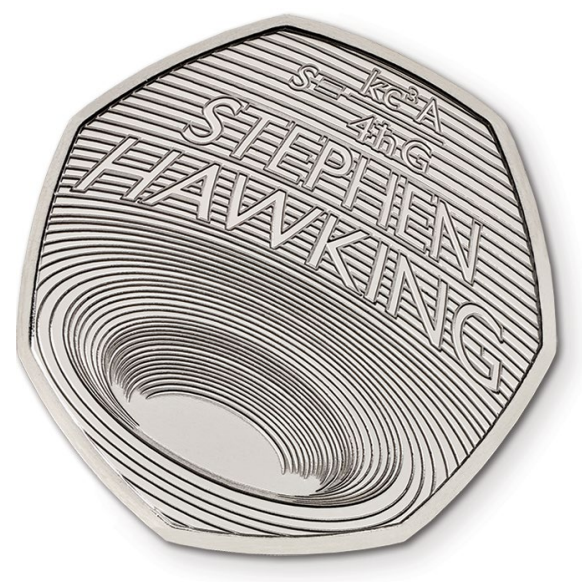

Credit: Royal Mint

Hawking is only the third Briton to be honoured with a coin within a year of death, his predecessors on that count being Winston Churchill and the Queen Mother. He also follows Isaac Newton, whose legacy was celebrated with a coin in 2017, and Charles Darwin, who was similarly commemorated in 2009. Hawking's coin is the first in a new series celebrating innovation in British science.

For reasons unknown, the tombstone for Hawking at Westminster Abbey features an equation expressing the temperature of Hawking radiation rather than the black hole entropy relation that much of the science world expected. Perhaps the minting of the new coin will appease Hawking's ghost.

Published online: 1 April 2019 https://doi.org/10.1038/s41567-019-0504-X

\footnotetext{
References

1. Hawking, S. W. Nature 248, 30-31 (1974).

2. Hawking, S. W. Stephen Hawking's 60 years in a nutshell. https://go.nature.com/2HEWhFF (1 December 2001).
} 